\title{
PERAN TEMPAT PELELANGAN IKAN PANIMBANG TERHADAP PENINGKATAN PENDAPATAN DAERAH KABUPATEN PANDEGLANG
}

\author{
Riesti Triyanti \\ Peneliti pada Balai Besar Riset Sosial Ekonomi Kelautan dan Perikanan \\ JI. KS. Tubun Petamburan VI Jakarta 10260 \\ Telp. (021) 53650162, Fax. (021)53650159 \\ Diterima 20 Maret 2011 - Disetujui 11 Mei 2011
}

\begin{abstract}
ABSTRAK
Kabupaten Pandeglang adalah daerah penghasil ikan ekonomis tinggi terbesar di Provinsi Banten. Kontribusi perikanan tertinggi berasal dari Tempat Pelelangan Ikan (TPI) Panimbangan. Tujuan penelitian ini adalah untuk mengidentifikasi dan menganalisis peran Tempat Pelelangan Ikan (TPI) khususnya TPI Panimbang dalam mendukung peningkatan pendapatan daerah Kabupaten Pandeglang. Penelitian dilakukan pada Bulan Juli dan Agustus Tahun 2010, di Desa Panimbang Jaya, Kecamatan Panimbang, Kabupaten Pandeglang. Data yang digunakan adalah data primer dan sekunder. Metode pengumpulan data primer menggunakan teknik wawancara, sedangkan data sekunder secara studi kepustakaan (desk study). Data yang diperoleh dianalisis secara deskriptif kualitatif. Hasil penelitian menunjukkan bahwa TPI Panimbang selain berperan dalam peningkatan produksi perikanan melalui retribusi/pemungutan perikanan, juga berperan sebagai objek pariwisata melalui pesta laut 'nadran', sehingga berkontribusi terhadap peningkatan pendapatan daerah Kabupaten Pandeglang.
\end{abstract}

Kata Kunci : tempat pelelangan ikan, pendapatan daerah, Desa Panimbang, Kabupaten Pandeglang

\section{Pendahuluan}

Tempat Pelelangan Ikan (TPI) memiliki manfaat yang beragam bagi nelayan, pedagang ikan dan masyarakat. Manfaat yang dirasakan adalah sebagai tempat untuk melakukan jual beli yang terbuka dan saling menguntungkan, harga yang disepakati umumnya tinggi (tidak merugikan), pasar lebih luas (luar kota, restoran dan pabrik pengolahan ikan), dan dapat memperoleh ikan dalam berbagai jenis. Bagi masyarakat sekitar dapat membeli ikan dengan harga yang lebih murah. Mengingat pentingnya TPI dalam menunjang laju perkembangan masyarakat dan membuat kemudahan dalam kegiatan masyarakat tersebut sehari-hari maka TPI sangat perlu untuk diadakan. TPI juga bermanfaat sebagai sarana berkumpul dan bersilaturrahmi antara masyarakat yang satu dengan yang lain yang tinggal disekitar TPI tersebut. Masyarakat nelayan yang tinggal di sekitar TPI berasal dari berbagai daerah pesisir yaitu Cirebon, Indramayu, dan Pekalongan yang umumnya memiliki tradisi mengadakan upacara sedekah laut atau disebut 'nadran' setiap tahun, sebagai bentuk rasa syukur kepada Tuhan Yang Maha Esa atas anugerah yang diberikan melalui hasil tangkapan ikan. Pesta laut 'nadran' dapat mendatangkan wisatawan. Berdasarkan hal diatas maka perlu dilakukan identifikasi mengenai peran TPI dalam meningkatkan pendapatan daerah Kabupaten Pandeglang di sektor kelautan dan perikanan.

\section{Kondisi Geografis Wilayah dan Karakteristik Masyarakat}

Kecamatan Panimbang merupakan kecamatan yang berada di sebelah selatan ibu kota Kabupaten Pandeglang dengan jarak $\pm 70 \mathrm{~km}$ dan luas wilayah \pm 9.774.914 $\mathrm{Ha}$, dengan batas wilayah Kecamatan
Panimbangan sebagai berikut (Hanafri, 2009):

$\begin{array}{ll}\text { Sebelah Utara } & \text { : Kecamatan Sukaresmi } \\ \text { Sebelah Timur } & \text { : Kecamatan Angsana } \\ \text { Sebelah Selatan } & \text { : Kecamatan Sobang dan Cigeulis } \\ \text { Sebelah Barat } & \text { : Selat Sunda }\end{array}$

Menurut data monografi Kecamatan Panimbang (2008), ada 6 (enam) desa yang termasuk dalam binaan Kecamatan Panimbangan, yaitu :

1. Desa Panimbang Jaya, dengan luas $1.056 .470 \mathrm{Ha}$

2. Desa Mekarjaya, dengan luas $606.024 \mathrm{Ha}$

3. Desa Gombong, dengan luas $796.750 \mathrm{Ha}$

4. Desa Mekarsari, dengan luas $2.309 .000 \mathrm{Ha}$

5. Desa Citeureup, dengan luas $1.705 .000 \mathrm{Ha}$

6. Desa Tanjung Jaya, dengan luas 3.301.740 Ha

Jumlah rumah tangga di Desa Panimbang Jaya sebanyak 3.001 KK yang merupakan jumlah penduduk yang terpadat diantara desa-desa yang ada di Kecamatan Panimbang. Hal ini dikarenakan Desa Panimbang Jaya mempunyai akses yang lebih baik diantara desa-desa lainnya. Akses tersebut adalah tempat berlabuh (Tempat Pelelangan Ikan) sehingga menyebabkan nelayan dari luar daerah singgah dan akhirnya menetap di Desa Panimbang Jaya. Mata pencaharian mayoritas di Desa Panimbang Jaya adalah pertanian (57 \%) sedangkan nelayan hanya $6 \%$ selain pengusaha, pedagang, PNS, maupun TNI/Polri, Agama yang dianut mayoritas masyarakat adalah Islam. Untuk tingkat pendidikan, umumnya berpendidikan rendah yaitu tamat Sekolah Dasar/Madrasah Ibtidaiyah, sedangkan pendidikan tertinggi adalah Sekolah Menengah Atas. 
Menurut Hanafri (2009), karakteristik modal sosial $^{1}$ masyarakat nelayan di Desa Panimbang Jaya cukup baik dalam hal tingkat resiprositas dan proaktif terhadap kegiatan sosial, perasaan saling mempercayai dan rasa aman, jaringan dan koneksi dalam komunitas, jaringan dan koneksi antar teman dan keluarga, toleransi, nilai hidup dan kehidupan, dan koneksi jaringan kerja diluar komunitas. Berdasarkan kuatnya modal sosial maka dapat didorong untk meningkatkan pendapatan rumah tangganya dengan cara berperan aktif dalam kegiatan Tempat Pelelangan Ikan (TPI) sehingga TPI lebih berperan dalam meningkatkan pendapatan masyarakat khususnya dan pendapatan daerah umumnya.
Pendapatan Daerah dan Pemungutan Retribusi Hasil Perikanan

Menurut Dinas Kelautan dan Perikanan Kabupaten Pandeglang (2010), potensi perikanan unggulan terbesar di Kabupaten Pandeglang adalah ikan tongkol sebesar 2.065.5 ton (40\%) dan kakap sebesar 1.301 .5 ton (25\%) yang merupakan ikan bernilai ekonomis tinggi dengan lokasi penangkapan di sekitar Panaitan Sumur, Selat Sunda, dan daerah Gunung Rakata.

Selain itu juga terdapat potensi lainnya berupa ikan kerapu (6 \%), cumi-cumi (13\%), udang (2\%) dan kerang (13\%). Besarnya potensi perikanan di Kabupaten

Tabel 1. Pendapatan Daerah Kabupaten Pandeglang, Tahun 2008-2010

\begin{tabular}{|c|c|c|c|c|}
\hline Kode & Uraian & 2008 & 2009 & 2010 (Jan-Agt) \\
\hline 4 & Pendapatan Daerah & $770,574,956,072$ & $821,589,030,807$ & $553,827,260,116$ \\
\hline 4.1 .1 & Hasil Pajak Daerah & 4,383,591,633 & 4,383,591,633 & $8,098,404,595$ \\
\hline 4.1 .2 & Hasil Retribusi Daerah & $17,371,808,850$ & $18,383,063,977$ & $7,649,213,747$ \\
\hline 4.1.2.02 & Retribusi Jasa Usaha & $1,873,070,050$ & $1,369,319,425$ & $845,255,920$ \\
\hline 4.1.2.02.01 & $\begin{array}{l}\text { Retribusi Pemakaian } \\
\text { Kekayaan Daerah dari sewa } \\
\text { tanah/alat berat/stumwales/ } \\
\text { sewa gedung (GP/Gd. Wanita) }\end{array}$ & $923,396,050$ & $592,736,425$ & $310,953,800$ \\
\hline 4.1.2.02.04 & Retribusi Terminal & $256,547,000$ & $230,985,000$ & $190,355,000$ \\
\hline 4.1.2.02.06 & $\begin{array}{l}\text { Retribusi tempat penginapan/ } \\
\text { pesanggrahan/vila }\end{array}$ & - & - & - \\
\hline 4.1.2.02.07 & $\begin{array}{l}\text { Retribusi penyediaan dan/ } \\
\text { atau penyedotan kakus }\end{array}$ & $13,125,000$ & $13,055,000$ & $4,515,000$ \\
\hline 4.1.2.02.08 & $\begin{array}{l}\text { Retribusi Rumah Potong } \\
\text { Hewan }\end{array}$ & $21,841,000$ & $21,843,000$ & $12,421,000$ \\
\hline 4.1.2.02.10 & $\begin{array}{l}\text { Retribusi tempat Rekreasi dan } \\
\text { Olahraga }\end{array}$ & $205,461,000$ & $210,000,000$ & $99,450,000$ \\
\hline 4.1.2.03 & Retribusi Perijinan Tertentu & $2,686,023,704$ & $4,201,029,456$ & $1,574,130,196$ \\
\hline 4.1 .3 & $\begin{array}{l}\text { Hasil Pengelolaan Kekayaan } \\
\text { Daerah yang dipisahkan }\end{array}$ & $5,571,997,122$ & $6,548,523,228$ & $7,877,554,471$ \\
\hline 4.1 .4 & $\begin{array}{l}\text { Lain-lain pendapatan daerah } \\
\text { yang sah }\end{array}$ & $6,153,048,566$ & $2,478,547,310$ & $1,183,267,925$ \\
\hline 4.2 & Dana Perimbangan & $697,532,647,336$ & $737,819,451,735$ & $499,512,545,379$ \\
\hline 4.3 & $\begin{array}{l}\text { Lain-lain Pendapatan Daerah } \\
\text { yang Sah }\end{array}$ & $39,561,862,565$ & $52,059,538,511$ & $35,049,538,705$ \\
\hline
\end{tabular}

Sumber: Dinas Pengelola Keuangan Pendapatan dan Aset Kab. Pandeglang, 2010 dalam Manadiyanto, dkk, 2010

${ }^{1}$ Modal sosial atau social capital dapat didefinisikan sebagai serangkaian nilai-nilai atau norma-norma informal yang dimiliki bersama diantara para anggota suatu kelompok yang memungkinkan terjalinnya kerjasama diantara mereka (Fukuyama, 2002 dalam Hanafri, 2009). 
Pandeglang menyebabkan daerah ini dikenal sebagai kota penghasil ikan sehingga dipandang sebagai sebuah potensi obyek untuk meningkatkan pendapatan asli daerah melalui pemungutan hasil perikanan/retribusi.

Untuk kegiatan yang ada di TPI, Pemerintah Kabupaten Pandeglang mengeluarkan Peraturan Daerah Kabupaten Pandeglang No. 12 Tahun 2001 tentang Retribusi Pasar Grosir dan atau Pertokoan yang diperuntukan bagi Penyelenggaraan Pelelangan Ikan. Pungutan retribusi pelelangan di Kabupaten Pandeglang berdasarkan ketentuan pasal 26 ayat (1) Perda No.12 Tahun 2001 ditetapkan sebesar 4\% dari harga/nilai kotor/raman pelelangan dan atau transaksi berbagai jenis barang di tempat pasar grosir yang dibebankan kepada pembeli/bakul sebesar $2 \%$ dan penjual/nelayan sebesar $2 \%$. Pungutan lain dalam kegiatan pelelangan ikan ditentukan berdasarkan pada hasil kesepakatan dan tidak boleh lebih dari 4\% (Pasal 27 ayat (1) Perda No.12 Tahun 2001), pungutan lain inilah yang nantinya akan diperuntukkan untuk biaya operasional TPI dan Dana Sosial (tabungan nelayan, dana paceklik, dana kecelakaan di laut dan asuransi nelayan). Keberadaan para pengelola TPI di Kabupaten Pandeglang pada saat ini juga berdasarkan atas Keputusan Kepala Dinas Kelautan dan Perikanan Kabupaten Pandelang No. 800.01/26-DKP/2010 tertanggal 4 Januari 2010 tentang Penunjukan/pengangkatan Manager dan kasir pada TPI se-Kabupaten Pandeglang. $\mathrm{Hal}$ tersebut dilakukan agar dalam penyelenggaraan dan pengelolaan TPI lebih tertib dan hasilnya lebih optimal.

Pendapatan Asli Daerah Kabupaten Pandeglang bersumber dari tiga dana yaitu (1) pendapatan asli daerah, (2) dana perimbangan, dan (3) Lain-lain pendapatan daerah yang sah. Jumlah retribusi TPI sebesar 22.29 \% (tahun 2008), 20.23 \% (tahun 2009), dan 26.92 \% (Januari s.d. Agustus tahun 2010) per retribusi jasa usaha. Nilai ini sangat besar dibandingkan retribusi lainnya dalam retribusi jasa usaha, misalnya retribusi terminal yang hanya mencapai $13.70 \%$, atau retribusi penjualan produksi usaha daerah bidang Pertanian hanya $1.21 \%$ pada tahun 2008.

Menurut Dinas Kelautan dan Perikanan (2010), dari 11 TPI di Kabupaten Pandeglang, sampai bulan Juli 2010 seluruh TPI belum mencapai target yang telah ditentukan. Sebagai contoh TPI Panimbangan, total retribusi sampai dengan bulan Juli tahun 2010 sebesar Rp 16.300.000,- (6.08\%) dari total retribusi seluruh TPI, padahal target Tahun 2010 sebesar Rp 80.000.000, - atau masih kurang $20.38 \%$ lagi. Bila dilihat dari total retribusi, nilai retribusi Tahun 2010 meningkat dibandingkan tahun-tahun sebelumnya karena ditetapkan Surat Keputusan Kepala Dinas Kelautan dan Perikanan Kabupaten Pandeglang No. 800.01/26DKP/2010. Dinas Kelautan dan Perikanan melakukan kesepakatan dengan pengurus-pengurus TPI berupa surat pernyataan tentang Pencapaian Target Retribusi Pelelangan Ikan Tahun Anggaran 2010 yang berisi bahwa:

1. Target Retribusi Pelelangan Ikan di TPI akan dipenuhi/ dilunasi selambat-lambatnya pada akhir tahun anggaran

2. Jumlah nilai retribusi yang harus dipenuhi atau dilunasi oleh Nanajer TPI sesuai dengan target yang telah disepakati

3. Apabila di kemudian hari atau batas akhir tahun anggaran tidak memenuhi Surat Pernyataan tersebut, maka Manajer TPI bersedia mengundurkan diri atau diberhentikan serta utang piutangnya akan diselesaikan sesuai dengan ketentuan yang berlaku.

Berdasarkan data TPI Panimbang Tahun 2010, selain retribusi sebesar $4 \%$ dari ramannya, TPI Panimbang juga melakukan pungutan lainnya untuk biaya operasional pelelangan ikan sebesar $2 \%$ dari raman. Biaya operasional tersebut dipotong untuk biaya-biaya seperti honorarium para karyawan TPI, biaya operasional mencakup ATK, karcis juragan, surat jalan dan laporan harian, pembayaran listrik, pembayaran sewa tempat lelang, dan perbaikan prasarana TPI. Biaya-biaya atas dana potongan tersebut tidak diperuntukkan bagi nelayan, misalnya dana sosial dan dana tabungan nelayan, sehingga tidak dirasakan manfaatnya secara langsung oleh nelayan. Perkembangan pungutan lain berupa biaya operasional pelelangan ikan sebesar 2\% di TPI Panimbang Tahun 2008-2009 disajikan pada Gambar 1.

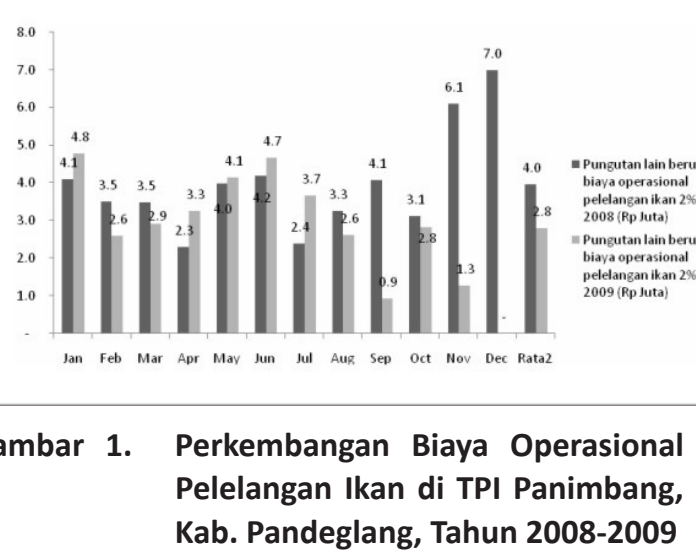

\section{Peningkatan Pendapatan Daerah melalui Pesta Laut 'Nadran'}

Pesta laut atau sedekah laut oleh masyarakat pesisir sering disebut dengan 'nadran'. Tujuan diselenggarakannya nadran adalah sebagai bentuk rasa syukur atas hasil tangkapan yang diberikan oleh Tuhan Yang Maha Esa dan bentuk doa agar nelayan selalu diberikan keselamatan dalam melaut. 


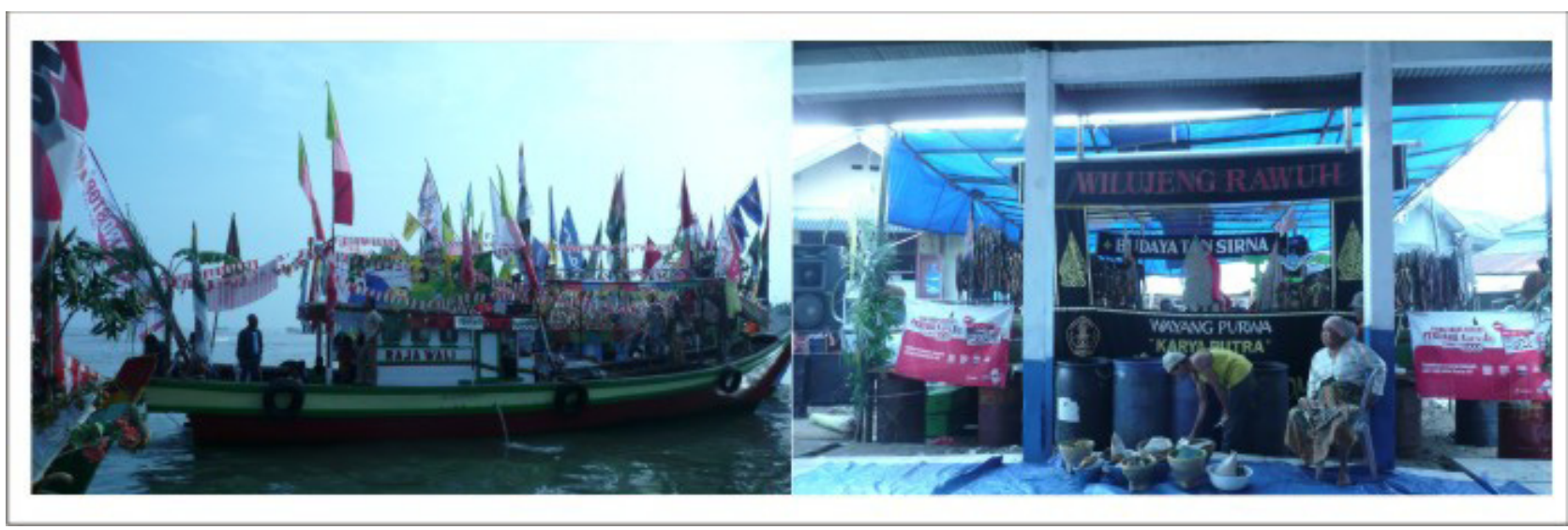

Gambar 2. Meriahnya Pesta Laut ‘Nadran’ di Desa Panimbang Jaya, Kabupaten Pandeglang, Tahun 2010

Tradisi nadran dilakukan setiap setahun sekali yang diikuti oleh seluruh masyarakat nelayan dan dihadiri oleh Bupati Kabupaten Pandeglang, Kepala Kecamatan, ulama, Direktorat Jenderal Hubungan Laut (coast guard), Polsek setempat, polisi air, dan Kepala Dinas Kelautan dan Perikanan Kabupaten Pandeglang. Dana yang digunakan berasal dari sumbangan berbagai pihak maupun dari biaya pemotongan biaya operasional pelelangan ikan. Pesta laut nadran dilakukan dengan meriah selama 4 (empat) hari. Pada hari pertama, dilakukan sunatan missal dan pengajian tabligh akbar (istighasah), ulama berpesan agar niat nadran diluruskan, jangan mengarah ke hal-hal syirik. Hari kedua dilanjutkan dengan pengobatan gratis dan pembagian sembako untuk anak yatim piatu keluarga nelayan dan nelayan jompo, sedangkan pada hari ketiga diadakan pembagian door prize berdasarkan kupon yang dijual kepada masyarakat. Puncak dari pelaksanaan nadran adalah pada hari keempat yaitu pemotongan dan pelarungan kerbau, lomba perahu hias yang diikuti oleh ratusan nelayan, dan pentas wayang kulit/golek dari Cirebon. Meriahnya pesta laut 'nadran' dapat dilihat pada Gambar 2.

Pesta laut 'nadran' digelar lagi setelah 7 (tujuh) tahun vakum. Pengunjung yang datang dalam acara berasal dari bermacam-macam daerah, antara lain: Jakarta, Sukabumi, Cirebon, Banten dan beberapa daerah disekitar Kabupaten Pandeglang. Menurut Dekan FISIP Universitas Swadaya Gunung Jati Cirebon, Dra Hariyani Agustina, MM dalam Anonimous (2011), 'nadran' memang bukan lagi sekadar upacara tradisi, melainkan bisa dijadikan bagian dari kegiatan kepariwisataan yang menghasilkan uang karena menarik untuk diperhatikan oleh wisatawan. Dalam acara ini, banyak terkandung nilai-nilai filosofis yaitu nilai solidaritas, etis, estetis, kultural, dan religius yang tercermin di setiap kegiatannya. Nilai-nilai tersebut dapat ditransformasikan dalam membangun kehidupan masyarakat kelautan ke taraf yang lebih maju dan lebih baik dari sisi pendidikan, ekonomi maupun solidaritas sosial budaya. Mengingat banyaknya nilai yang terkandung dalam acara ini, maka pesta laut ini perlu diadakan rutin setiap tahun. TPI sebagai wadah yang mengkoordinir kegiatan 'nadran' perlu didukung oleh pemerintah daerah sehingga dapat dikembangkan sebagai wisata unggulan di sektor kelautan selain produksi perikanan di sektor perikanan yang secara tidak langsung dapt meningkatkan pendapaan daerah.

\section{Kesimpulan}

Berdasarkan hasil identifikasi dan analisis maka dapat ditarik kesimpulan bahwa TPI berperan sebagai tempat transaksi pelelangan hasil penangkapan ikan dari nelayan kepada pembeli dan dapat menyumbang pendapatan daerah yang cukup besar ( \pm 20\%) di sektor perikanan. Selain itu TPI juga berperan sebagai daya tarik wisatawan melalui kegiatan pesta laut 'nadran' sehingga dapat dipertimbangkan menjadi objek pariwisata yang akhirnya dapat meningkatkan pendapatan daerah Kabupaten Pandeglang. Oleh karena itu perlu ditempuh langkahlangkah antara lain, perlu dipertimbangkan lagi mengenai kebijakan pemerintah khususnya Kementerian Kelautan dan Perikanan mengenai penghapusan retribusi terhadap hasil perikanan, sedangkan untuk pemerintah daerah Kabupaten Pandeglang perlunya penyelenggaraan acara 'nadran' setiap sekali setahun dan promosi yang lebih keras lagi akan dapat meningkatkan pendapatan daerah dalam bidang pariwisata bahari.

\section{Daftar Pustaka}

Anonimous. 2001. Peraturan Daerah Kabupaten Pandeglang Nomor 12 Tahun 2001 tentang Retribusi Pasar Grosir dan atau Pertokoan yang Diperuntukkan Bagi Penyelenggaraan Pelelangan Ikan. LD No.13 Th.2001 Seri B.7.

. 2008. Data Produksi Ikan TPI Panimbangan Tahun 2008. Desa Panimbang Jaya. Pandeglang. 
2005. Peraturan Daerah Provinsi Jawa Barat No. 5 Tahun 2005, tentang Penyelenggaraan dan Retribusi Tempat Pelelangan Ikan, Lembaran Daerah Provinsi Jawa Barat Tahun 2005, No. 10, Seri c.

2009. Data Produksi Ikan TPI Panimbangan Tahun 2009. Desa Panimbang Jaya. Pandeglang. 2009. Undang-Undang Nomor 28 Tahun 2009 tentang Pajak Daerah dan Retribusi Daerah. LN No.130 Th.2009 TLN No.5049.

2010. Keputusan Kepala Dinas Kelautan dan Perikanan Kabupaten Pandeglang Nomor 800.01/26-DKP/2010 Tahun 2001 tentang Penunjukan/Pengangkatan Manager dan Kasir pada Tempat Pelelangan Ikan (TPI) seKabupaten Pandeglang. Tgl. 04 Januari 2010.

. 2010. Data Pendapatan Daerah Kabupaten Pandeglang. Dinas Pengelola Keuangan Pendapatan dan Aset Kabupaten Pandeglang. Pandeglang.
.2010 . Statistik Perikanan Tahun 2009. Dinas Kelautan dan Perikanan Kabupaten Pandeglang. Pandeglang.

. 2011. Nadran, Tradisi Nelayan Pantura. http://wa-iki.blogspot.com/2011/03/nadrantradisi-nelayan-pantura.html. Tanggal akses : 25 April 2011.

Hanafri, M.I. 2009. Hubungan Modal Sosial dengan Kemiskinan Masyarakat Nelayan di Desa Panimbang Jaya, Pandeglang. Skripsi Institut Pertanian Bogor. Bogor.

Manadiyanto, Yulisti, M., Yusuf, R., Pramoda, R., Yanti, B.V,I., Apriliani, T., Nasution, Z. 2010, Riset Analisis Kebijakan Pembangunan Kelautan dan Perikanan : Evaluasi Dampak Penghapusan Retribus Terhadap Sektor Kelautan dan Perikanan. Laporan Teknis Tahun 2010 (Tidak Dipublikasikan). Balai Besar Riset Sosial Ekonomi Kelautan dan Perikanan. Balitbang KP - KKP. Jakarta 